\title{
Frequency and antibiotic susceptibility pattern of uropathogenic agents of urinary tract infections among asymptomatic diabetic patients in Okada community, southern Nigeria
}

\author{
Ruqayyah B. Adegbite, ${ }^{1}$ Hammed O. Ojokuku, ${ }^{2}$ Kamoru A. Adedokun, ${ }^{3,4}$ Musiliu A. Oyenike, ${ }^{5}$ \\ Ramat T. Kamorudeen ${ }^{6}$ \\ ${ }^{1}$ Department of Medical Laboratory Science, Igbenedion University, Okada, Edo State, Nigeria; ${ }^{2}$ Department of \\ Medical Laboratory Services, General Hospital, Lagos Island, Lagos State, Nigeria; ${ }^{3}$ Department of Chemical \\ Pathology, College of Medicine, University of Ibadan, Ibadan, Oyo State, Nigeria; ${ }^{4}$ Department of Oral Pathology, \\ King Saud University Medical City, Riyadh, Kingdom of Saudi Arabia; ${ }^{5}$ Department of Medical Laboratory Science, \\ College of Health Sciences, Ladoke Akintola University of Technology, Osogbo, Osun State, Nigeria; ${ }^{6}$ Department of \\ Maternal and Children Welfare, Hospital Management Board Asubiaro, Osogbo, Osun State, Nigeria
}

\section{Summary}

Massive evidence showed that patients with diabetes have a high risk of urinary tract infections. We studied the frequency of potential urinary uropathogens among diabetic patients and identified their antimicrobial susceptibility patterns.

This was a prospective hospital-based study conducted at the Department of Medical Laboratory Science, Igbinedion University Teaching Hospital, Southern Nigeria, between January 2014 and May, 2014. We included 240 previously confirmed diabetic patients (women, n=70 and men, n=170) who were regularly followed up without prior treatment with any antimicrobial therapy and within the age range of 26-75 years. Patient personal history data and midstream urine samples were collected. Urine samples were pro-

Correspondence: Kamoru A. Adedokun, King Saud University Medical City, Department of Oral and Pathology, DUH, Riyadh, Kingdom of Saudi Arabia.

Tel.: +96.6552442026.

E-mail: adeolokun@yahoo.com

Key words: Antimicrobial susceptibility; asymptomatic bacteriuria; diabetes mellitus; urinary tract infection; uropathogens.

Contributions: the authors contributed equally.

Conflict of interest: the authors declare no potential conflicts of interest.

Funding: none.

Received for publication: 30 January 2019

Revision received: 29 March 2019.

Accepted for publication: 29 April 2019.

(C) Copyright R.B. Adegbite et al., 2019

Licensee PAGEPress, Italy

Microbiologia Medica 2019; 34:8077

doi:10.4081/mm.2019.8077

This article is distributed under the terms of the Creative Commons Attribution Noncommercial License (by-nc 4.0) which permits any noncommercial use, distribution, and reproduction in any medium, provided the original author(s) and source are credited. cessed in the laboratory following a Standard Laboratory Protocol.

Escherichia coli, Staphylococcus aureus, Klebsiella spp. and Candida spp. were isolated in this study. A significant bacteriuria count was estimated in $12.5 \%$ of the sampled population, while 17.1 and $10.6 \%$ were estimated in females and males, respectively. Similarly, candiduria was found in female, male and total sample in $12.9 \%, 2.9 \%$, and $5.8 \%$, in that order. According to antimicrobial sensitivity testing, the Gram-negative bacilli isolated were highly sensitive to nitrofurantoin followed by ofloxacin, gentamycin and least sensitive to cefuroxime. Estimation of potential uropathogens among asymptomatic diabetic populations may avert possible urinary tract infections and their possible complications ultimately and thus prevent possible advanced renal diseases.

\section{Introduction}

Diabetes mellitus alters the genitourinary system where urinary tract infection (UTI) could prompt urological problems, such as dysuria, organ damage and sometimes even death due to complicated UTIs involving pyelonephritis (21), emphysematous cystitis, renal abscesses and renal papillary necrosis (16).

UTI has been repeatedly reported in diabetic patients $(3,8,20,22)$. Several mechanisms unique to diabetes have been implicated as potential factors that may increase the risk of developing UTI (3). Some of these factors involve increase in urine glucose level that may possibly enrich growth of pathogenic bacteria (8). Several reports noted that high renal parenchymal glucose level supports a conducive milieu towards multiplication of these uropathogens, thus indicating a driving factor for developing pyelonephritis and other renal complications - emphysematous pyelonephritis and renal abscesses $(20,22)$. Furthermore, various impairments to the immune system affecting cellular, innate and humoral immunity may contribute to the development of UTIs in diabetics $(5,9)$.

The frequency of UTI in diabetic patients has been assessed to vary from $8 \%$ to $26 \%$ in different regions $(8,10,28)$. Estimating frequency of potential uropathogens along with their antimicrobial drug susceptibility may help improve the management of diabetic patients who are most times asymptomatic and thus help prevent UTIs and their complications. 


\section{Materials and Methods}

\section{Study area}

This study was carried out at Igbinedion University Teaching Hospital (IUTH) Okada, Edo State, Southern Nigeria after obtaining ethical approval. All participants gave informed consent.

\section{Study population}

The sample comprised male $(n=170)$ and female $(n=70)$ patients attending the diabetes clinic; their age ranged from 26 to 75 yrs. Detailed information of the patients regarding age, sex and plasma glucose level at time sampling was obtained during the exercise.

\section{Selection criteria}

\section{Inclusion criteria}

Diagnosis of diabetes was based on glucose values (fasting plasma glucose of $\geq 126 \mathrm{mg} / \mathrm{dL}$; 2-hour post prandial $\geq 200 \mathrm{mg} / \mathrm{dL}$ ) according to WHO criteria (27).

\section{Exclusion criteria}

We excluded patients on antibiotic therapy and pregnant women who have been reported in previous studies with possible increase in incidence of UTIs, owing to pregnancy-associated urinary stasis and vesicoureteral reflux $(13,24)$.

\section{Specimen collection}

Clean voided midstream urine samples were collected into sterile universal containers with identification number, sex and age well written on the bottles after giving proper instructions. Every individual patient submitted one specimen each. The samples were then transported to the laboratory immediately and for processing within 30 to 60 minutes of voiding.

\section{Isolation of microorganisms}

Each urine sample was properly mixed before streaking on agar plates with the aid of a sterile wire loop. The urine samples were inoculated on dried plates of MacConkey agar, cysteine lactose electrolyte deficient (CLED) agar, mannitol salt agar, and Sabouraud Dextrose agar (Oxoid, UK). The plates were incubated aerobically at $37^{\circ} \mathrm{C}$ for $24-48 \mathrm{hrs}$ and were observed for growth after incubation. The isolates were considered with the colony count $>10^{5} \mathrm{CFU} / \mathrm{mL}$ (1).

\section{Characterization and identification of isolated microorganisms}

Colony identification and confirmation were done for the bacterial isolates using standard microbiological techniques including Gram staining reactions, colony growth morphology on media, lactose fermentation, catalase, coagulase, oxidase, indole, citrate utilization and urease tests. Fungal isolates on the Sabouraud agar plates were characterized and identified as Candida spp. by colony morphology and Gram staining, while phenotypic identification was furthered using germ tube test (GTT) for speciation of the yeast (12).

\section{Antimicrobial sensitivity testing}

Antibiotic susceptibility of the isolates was carried out on sterile Mueller Hinton agar using the Kirby Bauer disc diffusion method (1). The agar surface was evenly inoculated using a sterile swab loaded with a cell suspension adjusted to the turbidity of 0.5 McFarland standards (12). The following antibacterial disks were used: ceftazidine $(30 \mu \mathrm{g})$, cefuroxime $(30 \mu \mathrm{g})$, gentamicin $(10 \mu \mathrm{g})$, ciprofloxacin $(5 \mu \mathrm{g})$, ofloxacin $(5 \mu \mathrm{g})$, amoxicillin-clavulanic acid $(30 \mu \mathrm{g})$, nitrofurantion $(300 \mu \mathrm{g})$, ampicillin $(10 \mu \mathrm{g})$, erythromycin $(15 \mu \mathrm{g})$ and ceftriaxone $(30 \mu \mathrm{g})(\mathrm{BioRad})$ following the manufacturer instructions. The plates were left out on the bench for $30 \mathrm{mins}$ before incubation.

\section{Measurement of inhibition zones}

After 24 hours of incubation at $37^{\circ} \mathrm{C}$, the cultured plates were examined and the diameter of inhibitory zones was measured. Susceptibility or resistance was determined according to the CLSI guidelines and published papers $(7,12,23)$.

\section{Statistical}

The results obtained in this study were analysed using descriptive statistics: proportion, frequency and percentage to assess the level of variability.

\section{Results}

The cases with positive cultures of bacterial isolates were 12 $(17.1 \%)$ females and $18(10.6 \%)$ males; overall, the cases of bacteriuria were $30(12.5 \%)$.

Similarly, candiduria was found in $14(5.8 \%)$ of the whole sample: $9(12.9 \%)$ in females, and $5(2.9 \%)$ in males (Table 1$)$.

Different age groups showed varying proportions of positive cases of uropathogens among the diabetics. Highest frequencies ( $46.7 \%$ cases) of asymptomatic bacteriuria were found among the age group of $36-45$ years, followed by $40 \%$ cases in $46-55$ yrs group. Other age groups (26-35 and 55-65 years) equally had $6.6 \%$ cases each, respectively (Table 2 ).

Frequency of total significant uropathogens in diabetic patients shows that $22(50.0 \%)$ were Gram negative bacilli (GNB) constituting $16(36.4 \%)$ Escherichia coli and 6 (13.6\%) Klebsiella spp. Other bacterial isolates were Gram positive cocci (GPC) consisting only Staphylococcus aureus $(\mathrm{n}=8 ; 18.2 \%)$, while the remaining significant isolates were $14(31.8 \%)$ Candida spp. (Figure 1).

Also, with antibiotics susceptibility testing, GNB was found most sensitive to nitrofurantoin followed by ofloxacin, gentamycin and least sensitive to cefuroxime (Table 3).

\section{Discussion}

Urinary tract infection (UTI) is a possible clinical problem in people suffering from diabetes mellitus. Many studies previously reported prevalence of asymptomatic bacteriuria (ASB) in diabetic population as high as $8-26 \%(10,22,28)$. This is in agreement with the present study. We found frequency of $12.5 \%$ of diabetic patients in our sample population as ASB, while 17.1 and $10.6 \%$ indicated the percentage frequencies for female and male subgroups, respectively.

Importantly, women were identified with more significant frequencies of uropathogenic agents in this study and this was in concordance with previous studies $(2,14,15)$. This may be due to a short urethra length which is in proximity to the moist and warm vulvar region and perianal area or attributed to higher level of recurrence of UTI in women (11). Generally, these areas are often colonized by enteric bacteria $(14,15)$. This anatomical position often allows bac- 
teria to travel up the urinary tract length and thus become uropathogenic in this new environment $(4,18)$. Generally, we presumed that increase in glucose concentrations of diabetic's urinary flow along the tract may possibly play a contributory role in this case and could set off UTI in diabetics if left uncontrolled (26).

In addition, the results of our study indicated that increase in age may not influence a chance or occurrence of UTI. Likewise, it was previously reported that age was not associated with complicated course of UTIs in patients with diabetes thus not a useful predictor (11). Although, UTIs were not noticed during patients' recruitment in our study. On the other hand, there are different reports in contrast to our findings. Some studies show that ASB increases with age, and is also associated with urinary tract abnormalities $(4,18)$.

Further, the largest number of uropathogens isolated in the present study was Gram negative bacilli (GNB). This corroborates a bacteriological study where Gram negative enteric organisms, such as E. coli, Klebsiella spp. and Proteus spp., are implicated with ASB (26). Likewise, the pattern of isolation of organism in our study was similar to a previous result involving various regions implicating GNB, particularly E. coli, as the commonest pathogen of both ASB and UTIs $(19,26)$. Also, our study is in agreement with a report from India population, where $E$. coli is the most frequently reported $(64.3 \%)$ uropathogens, followed by $S$. aureus (21.4\%) and Klebsiella spp. (14.3\%) (6). In tandem with the current study, similar frequency of $E$. coli was predominantly isolated, followed by $S$. aureus before Klebsiella spp. Although it was very infrequent, we found some candida growths during post-culture characterization and identification of the organisms. This is in agreement with previous finding where type 2 diabetes is reported as a risk factor for fungal UTI, attributed to Candida spp. as the commonest fungal agent (25).

Furthermore, our findings on antimicrobial susceptibility testing showed that nitrofurantoin was the most sensitive drug followed by ofloxacin and gentamycin, against the isolated uropathogens. This is in contrary to some reports where quinolones were found most effective against isolated GNB (28). This may be attributable to changing trends in antimicrobial susceptibility pattern from place to place, with possibility of diverse genetic varia- tions. Moreover, our results showed that the isolated organisms were resistant to majority of the first line antibiotics and may thereby require the need of newer and more effective antibiotics for safe treatment.

\section{Conclusions}

Findings from this study showed that significant asymptomatic bacteriuria accounted for frequency of $12.5 \%$ in total dia-

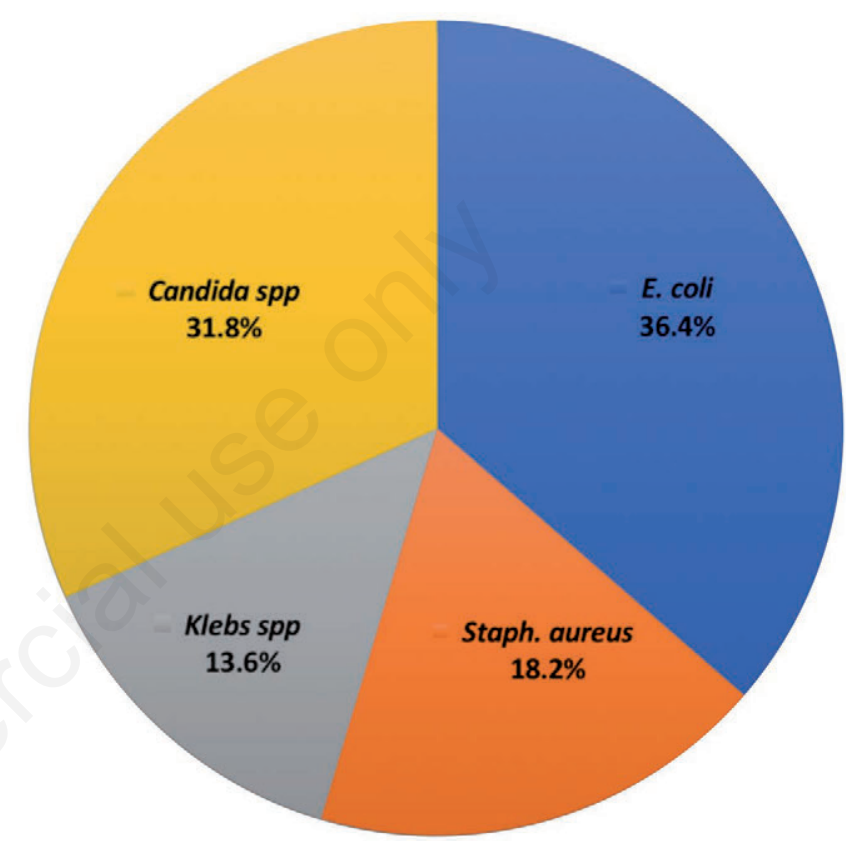

Figure 1. Frequency of isolates in asymptomatic diabetic patients.

Table 1. Gender distribution in diabetic patients.

\begin{tabular}{llccc} 
Uropathogens & Gender & Frequency (\%) & No. significant positive culture cases & No. cases examined \\
Bacterial isolates & F & 17.1 & 12 & 70 \\
& M & 10.6 & 18 & 170 \\
& Total & 12.5 & 30 & 240 \\
Candida spp. & F & 12.9 & 9 & 70 \\
& M & 2.9 & 5 & 170 \\
& Total & 5.8 & 14 & 240 \\
\hline
\end{tabular}

Table 2. Age distribution of asymptomatic bacteriuria in diabetic patients.

\begin{tabular}{lccc} 
Age group & Male, $\%$ & Female, \% & Total population, $\mathbf{n}$. (\%) \\
$26-35$ years & 2 & 0 & $2(6.6)$ \\
$36-45$ years & 10 & 4 & $14(46.7)$ \\
\hline $46-55$ years & 6 & 6 & $12(40)$ \\
$55-65$ years & 0 & 2 & $2(6.6)$ \\
\hline Total & 18 & 12 & $30(100)$ \\
\hline
\end{tabular}


Table 3. Antimicrobial sensitivity/resistance pattern of bacterial isolates in asymptomatic diabetic patients.

\begin{tabular}{|c|c|c|c|c|c|c|}
\hline \multirow{2}{*}{$\begin{array}{l}\text { Antimicrobials, } \\
\text { sensitive }\end{array}$} & \multicolumn{2}{|c|}{ Escherichia coli } & \multicolumn{2}{|c|}{ Klebsiella spp. } & \multicolumn{2}{|c|}{ Staphylococcus aureus } \\
\hline & Male $(n=10)$ & Female $(n=6)$ & Male $(n=2)$ & Female $(n=4)$ & Male $(n=6)$ & Female $(n=2)$ \\
\hline Ceftazidine & $0 / 10$ & $0 / 6$ & $2 / 2$ & $2 / 4$ & $0 / 6$ & $0 / 2$ \\
\hline Cefuroxime & $0 / 10$ & $0 / 6$ & $2 / 2$ & $0 / 4$ & $0 / 6$ & $0 / 2$ \\
\hline Gentamicine & $6 / 10$ & $4 / 6$ & $0 / 2$ & $2 / 4$ & $4 / 6$ & $2 / 2$ \\
\hline Ciprofloxacin & $4 / 10$ & $6 / 6$ & $0 / 2$ & $2 / 4$ & - & - \\
\hline Ofloxacin & $6 / 10$ & $6 / 6$ & $0 / 2$ & $2 / 4$ & $4 / 6$ & $2 / 2$ \\
\hline Augmentin & $4 / 10$ & $0 / 6$ & $0 / 2$ & $0 / 4$ & $2 / 6$ & $0 / 2$ \\
\hline Nitrofurantion & $10 / 10$ & $6 / 6$ & $0 / 2$ & $4 / 4$ & - & - \\
\hline Ampicillin & $0 / 10$ & $0 / 6$ & $0 / 2$ & $0 / 4$ & - & - \\
\hline Erythromycin & - & - & - & - & $6 / 6$ & $2 / 2$ \\
\hline Ceftriaxone & - & - & - & - & $0 / 6$ & $0 / 2$ \\
\hline
\end{tabular}

betic population, while 17.1 and $10.6 \%$ were estimated in females and males respectively. Significant numbers of positive isolates of Candida spp. in female, male and sampled populations were $12.9 \%, 2.9 \%$, and $5.8 \%$, in that order. We found that E. coli and Candida spp. were the most frequent potential uropathogens in diabetic patients, even though the patients were asymptomatic. Consequently, investigation or screening for these critical organisms could be advisable for improved management and prevention of full blown UTI and its potential complications or advanced renal problems. For this reason, assessment of potential significant uropathogens is recommended for diabetic population.

\section{References}

1. Bauer AW, Kirby WM, Sherris JC, Turck M. Antibiotic susceptibility testing by a standardized single disk method. Am J Clin Pathol 1966;45:493-6.

2. Brown JS, Wessells H, Chancellor MB, et al. Urologic complication of diabetes. Diabet Care 2005;8:177-85.

3. Chen SL, Jackson SL, Boyko EJ. Diabetes mellitus and urinary tract infection: epidemiology, pathogenesis and proposed studies in animal models. J Urol 2009;182:S51-6.

4. Colgan R, Nicolle LE, McGlone A, Hooton TM. Asymptomatic bacteriuria in adults. Am Fam Physician 2006;74:985-90.

5. Delamaire M, Maugendre D, Moreno M, et al. Impaired leucocyte functions in diabetic patients. Diabet Med 1997;14:29-34.

6. Ebie M, Kandaki-Olukemi YT, Ayanbadejo J, Tanyigna, KB. UTI infections in a Nigerian Military Hospital. Niger J Microbiol 2001;15:31-7.

7. ElFeky DS, Gohar NM, El-Seidi EA, et al. Species identification and antifungal susceptibility pattern of Candida isolates in cases of vulvovaginal candidiasis. Alexandria J Med 2015;52:269-77.

8. Fünfstück R, Nicolle LE, Hanefeld M, Naber KG. Urinary tract infection in patients with diabetes mellitus. Clin Nephrol 2012;77:40-8.

9. Geerlings SE, Brouwer EC, Van Kessel KC, Gaastra et al. Cytokine secretion is impaired in women with diabetes mellitus. Eur J Clin Invest 2000;30:995-1001.

10. Geerlings SE, Stolk RP, Camps MJ, et al. Asymptomatic bacteriuria can be considered a diabetic complication in women with diabetes mellitus. Adv Exp Med Biol 2000;485:309-14.

11. Hosking DJ, Bennet T, Hampton JR. Diabetic autonomic neuropathy. Diabetes 1978;27:1043-55.

12. Howell SA, Hazen KC. Candida, Cryptococcus and other yeasts of medical importance. In: Versalovic J, Carroll KC, Funke G, et al, eds. Manual of clinical microbiology. 10th ed. Washington, DC: ASM Press; 2012; pp 1793-821.

13. Johnson EK. Urinary Tract Infections in Pregnancy. Medscape 2017. Available from: https://emedicine.medscape.com/article/452604-overview\#showall

14. Leobovici L, Yehezkelli Y, Porter A, et al. Influence of diabetes and glycemic control on the characteristics and outcome of common infections. Diabet Med 1996;13:457-63.

15. Meiland R, Geerlings SE, Stolk RP, et al. Asymptomatic bacteriuria in women with diabetes mellitus. Arch Int Med 2006;166:2222-7.

16. Mnif MF, Kamoun M, Kacem FH, et al. Complicated urinary tract infections associated with diabetes mellitus: pathogenesis, diagnosis and management. Indian J Endocrinol Metab 2013;17:442-5.

17. NCCLS. National Committee for Clinical Laboratory Standards Performance standards for Antimicrobial susceptibility testing. 26th edition. CLSI supplement M100S, Wayne, PA, USA.

18. Nicolle LE. Asymptomatic bacteriuria. Curr Opin Infect Dis 2014;27:90-6.

19. Njoku CO, Ezissi NH, Amadi AN. Observations on bacterial infections of urinary tract patients. Int J Environ Health Hum Dev 2001;2:57-61.

20. Park BS, Lee SJ, Kim YW, et al. Outcome of nephrectomy and kidney-preserving procedures for the treatment of emphysematous pyelonephritis. Scand J Urol Nephrol 2006;40:332-8.

21. Saleem M, Daniel B. Prevalence of urinary tract infection among patients with diabetes in Bangalore city. Int J Emerg Sci 2011;1:133-42.

22. Schneeberger C, Kazemier BM, Geerlings SE. Asymptomatic bacteriuria and urinary tract infections in special patient groups: women with diabetes mellitus and pregnant women. Curr Opin Infect Dis 2014;27:108-14.

23. Shokohi T, Badali H, Amirrajab N, et al. In vitro activity of five antifungal agents against Candida albicans isolates, Sari, Iran. Curr Med Mycol 2016;2:34-9.

24. Smaill F. Asymptomatic bacteriuria in pregnancy. Best Pract Res Clin Obstet Gynaecol 2007;21:439-50. 
25. Sobel JD, Fisher JF, Kauffman CA, Newman CA. Candida urinary tract infections - epidemiology. Clin Infect Dis 2011;52: S433-6.

26. Venkatesan KP, Chander S, Loganathan K, Victor K. Study on asymptomatic bacteriuria in diabetic patients. IJCMR 2017;4: 480-3.

27. World Health Organization. Definition and diagnosis of diabetes mellitus and intermediate hyperglycaemia: Report of a WHO/IDF Consultation. Geneva: WHO; 2006. Available from: http:// whqlibdoc.who.int/publications/2006/9241594934_eng.pdf

28. Zhanel GG, Nicolle LE, Harding GK. Prevalence of asymptomatic bacteriuria and associated host factors in women with diabetes mellitus. The Manitoba Diabetic Urinary Infection Study Group. Clin Infect Dis 1995;21:316-22. 